Supporting Information

\title{
A Multifunctional and High-Sensitive Sensor Capable of Detecting Humidity, Temperature and Flow Stimuli Using an Integrated Microheater
}

Jin Wu, ${ }^{\text {a }}$ Zixuan Wu, ${ }^{\mathrm{a}}$ Haojun Ding, ${ }^{\mathrm{a}}$ Yaoming Wei, ${ }^{\mathrm{a}}$ Xing Yang, ${ }^{\mathrm{a}}$ Zhenyi Li, ${ }^{\mathrm{a}}$ Bo-Ru Yang, ${ }^{\text {a }}$ Chuan Liu, ${ }^{\text {a }}$ Lin Qiu*c and Xiaotian Wang*b

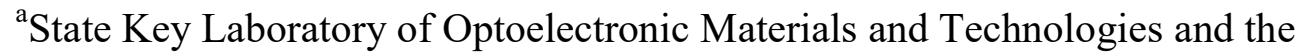

Guangdong Province Key Laboratory of Display Material and Technology, School of Electronics and Information Technology, Sun Yat-sen University, Guangzhou 510275, China

${ }^{\mathrm{b}}$ School of Chemistry, Beihang University, 100191 Beijing, P. R. China

${ }^{\mathrm{c}}$ School of Energy and Environmental Engineering, University of Science and Technology Beijing, 100083 Beijing, P. R. China

*To whom correspondence should be addressed. E-mail: wujin8@mail.sysu.edu.cn or qiulin@ustb.edu.cn or wangxt@buaa.edu.cn 

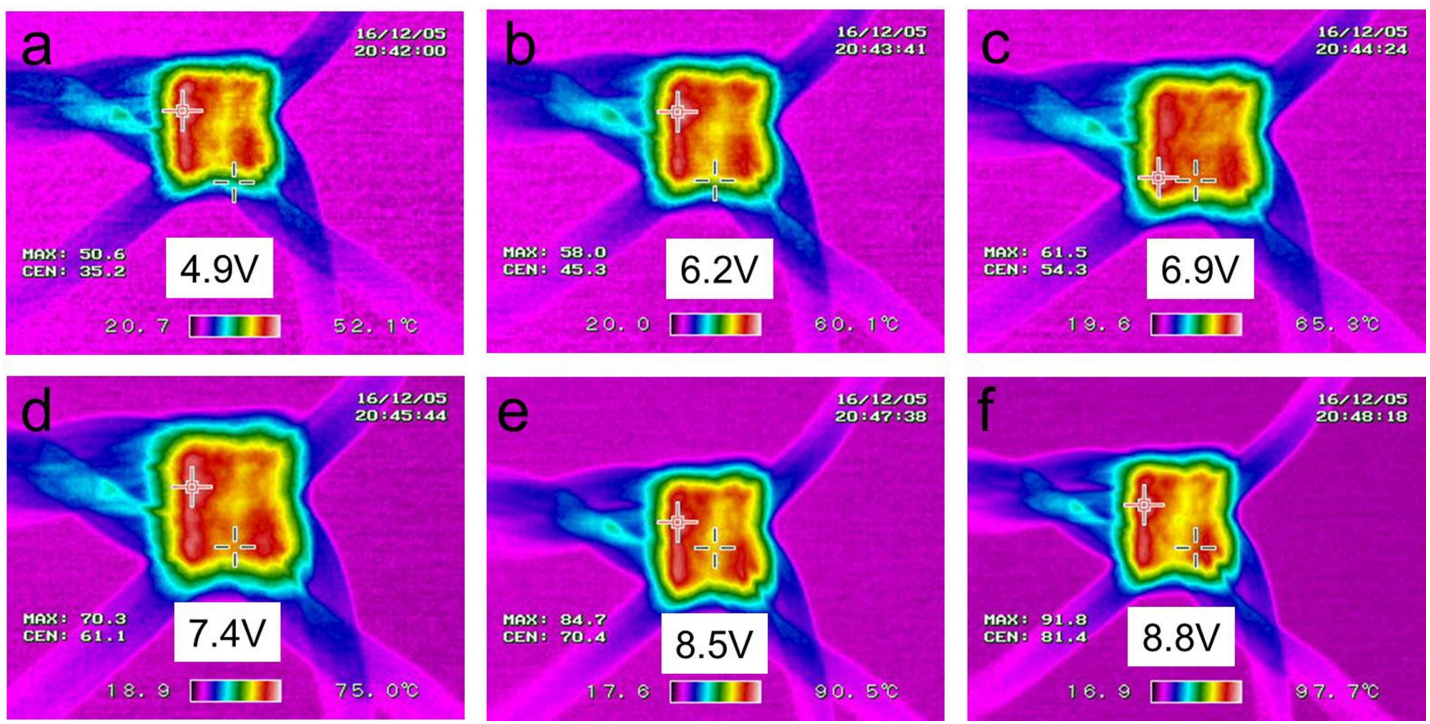

Figure S1. Thermographic images of the sensor chip captured by the infrared camera (TYPE F30W, NEC Avio Infrared Technologies Co., Ltd.) when the DC voltages of 4.9 $\mathrm{V}(\mathrm{a}), 6.2 \mathrm{~V}(\mathrm{~b}), 6.9 \mathrm{~V}(\mathrm{c}), 7.4 \mathrm{~V}(\mathrm{~d}), 8.5 \mathrm{~V}(\mathrm{e})$, and $8.8 \mathrm{~V}(\mathrm{f})$ were applied on the microheater. The temperature of the sensor chip increased monotonically with the voltage. 


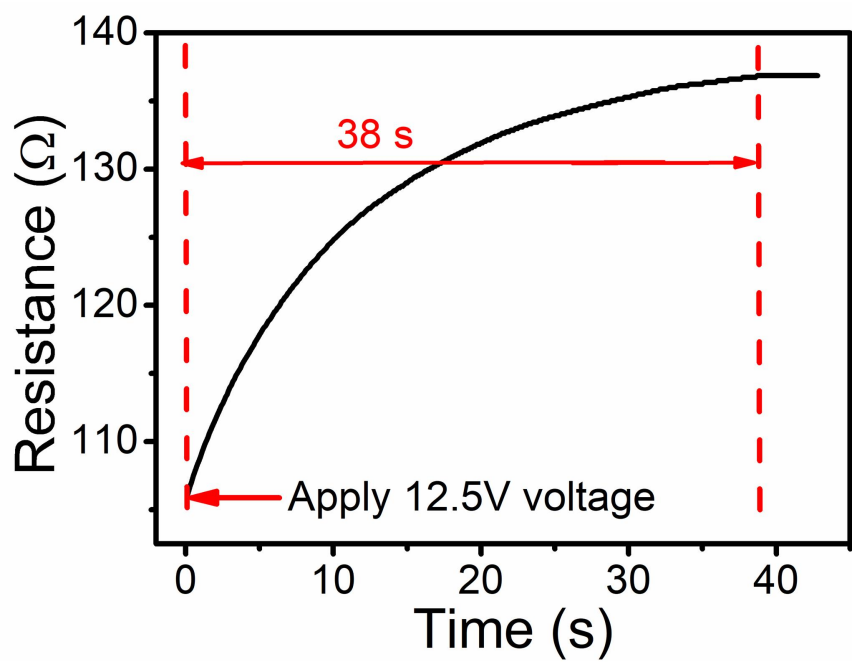

Figure S2. Dynamic resistance change of the microheater when a DC voltage of 12.5 V was applied. 


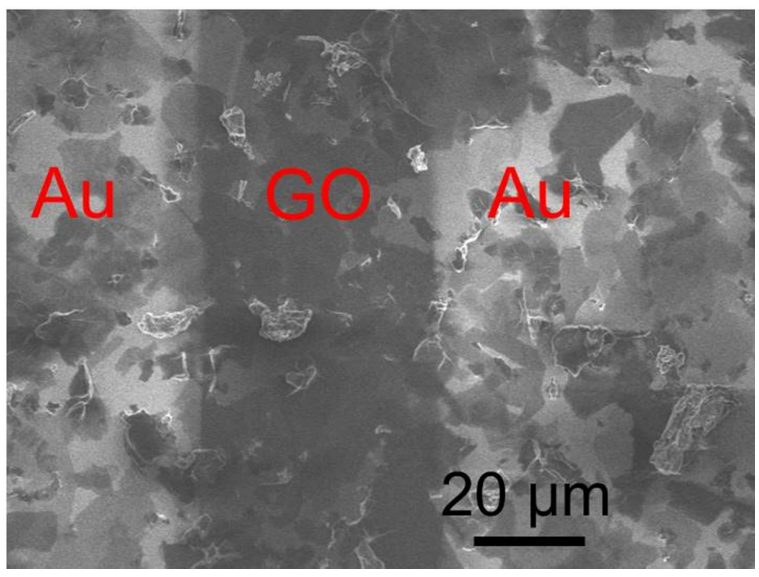

Figure S3. SEM image of the GO sheets filled in one of the gaps on the Au IEs. The SEM images of GO were obtained on FE-SEM 7600, which was also equipped with INCA (INCA 4.15; Oxford Instruments) to carry out the energy-dispersive X-ray (EDX) spectra analysis. 

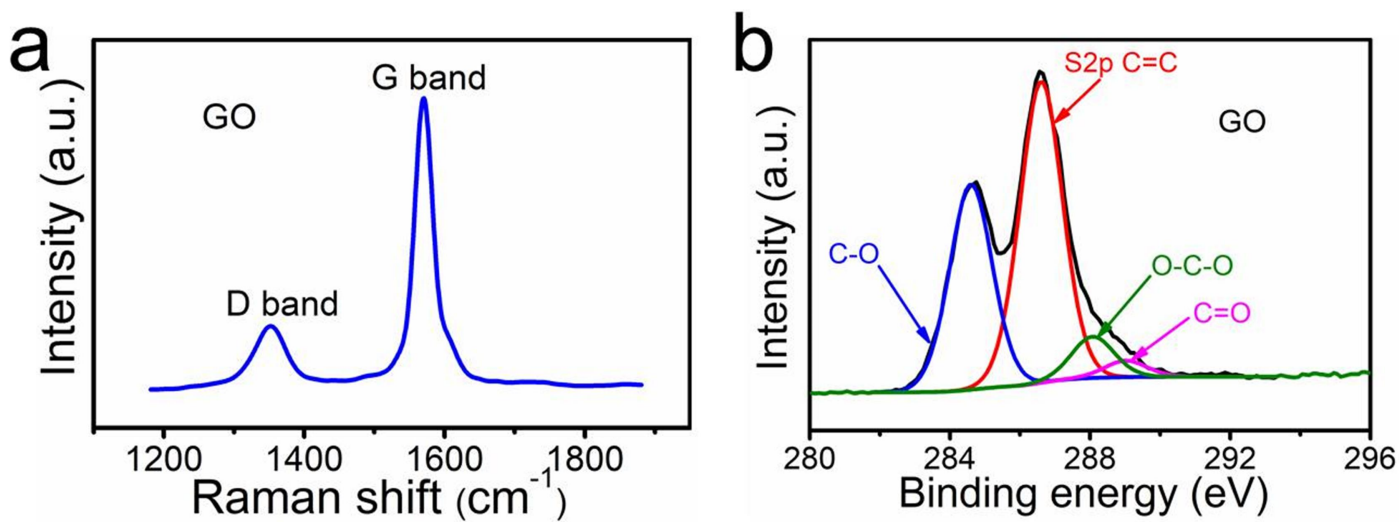

Figure S4. Raman (a) and X-ray photoelectron spectroscopy (XPS) spectra (b) of GO at room temperature. Raman spectra were obtained using a spectrophotometer (alpha300 R from WITec) with a $514 \mathrm{~nm}$ laser. XPS spectra were acquired using a Kratos XSAM 800 spectrometer with a Mg Ka (1253.6 eV) X-ray source. 


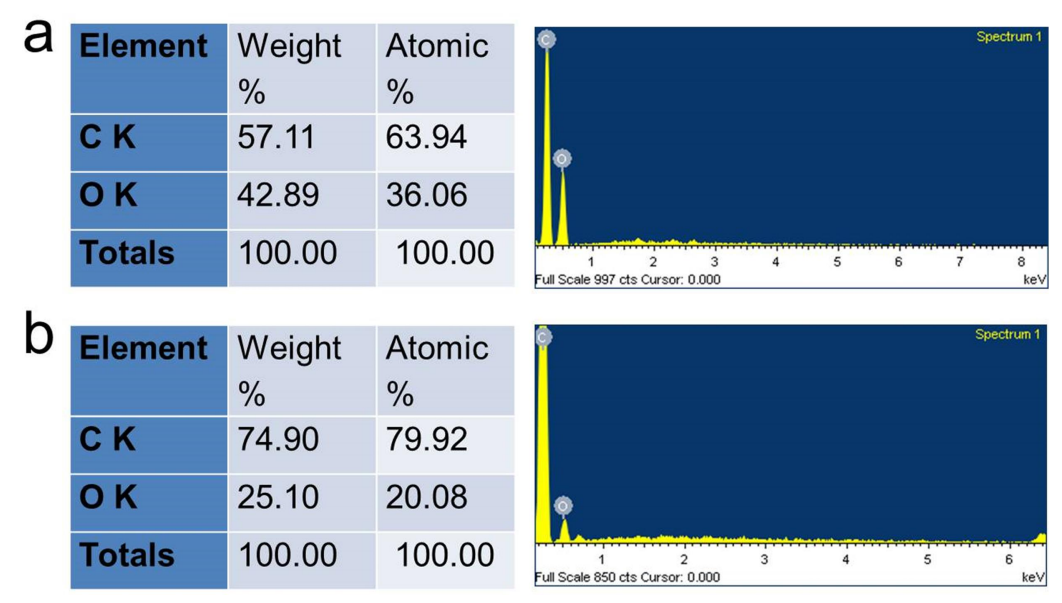

Figure S5. EDX spectra of GO before (a) and after (b) heating at $146{ }^{\circ} \mathrm{C}$ for $30 \mathrm{~min}$, which reveals a significant deoxygenation and reduction after thermal treatment. 


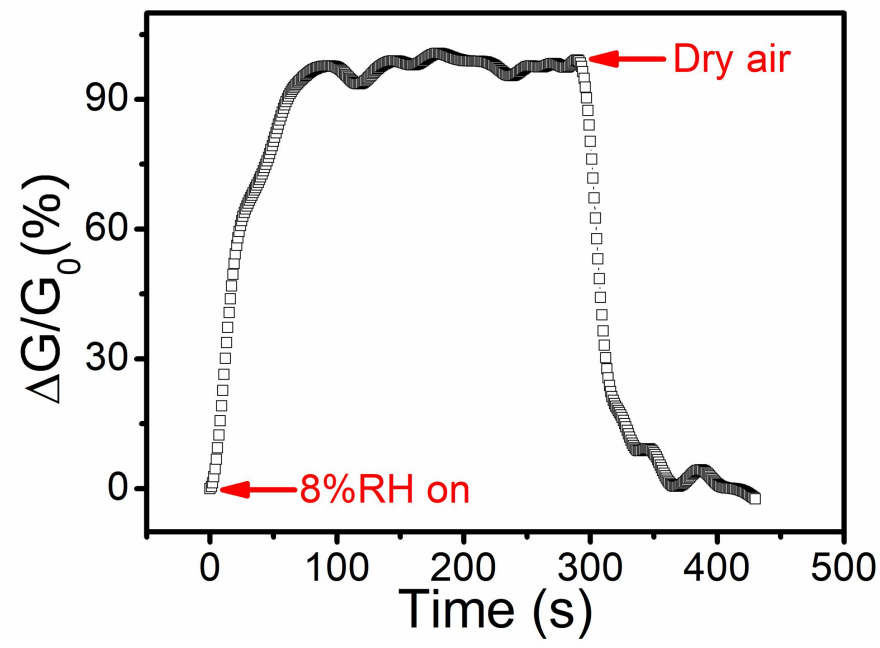

Figure S6. Magnified dynamic response of the GO humidity sensor to $8 \% \mathrm{RH}$. 


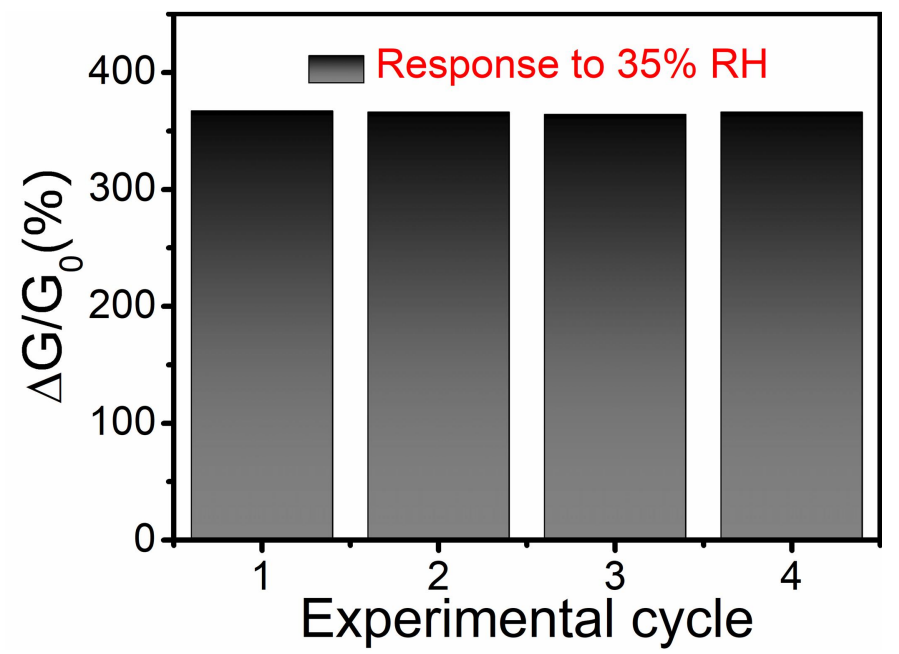

Figure S7. Plot of the quantitative response of the humidity sensor to $35 \% \mathrm{RH}$ versus experimental cycles. 
Table S1. Comparison of humidity sensors made of different materials.

\begin{tabular}{|c|c|c|c|c|c|}
\hline Sensing materials & $\begin{array}{l}\text { Detection } \\
\text { range } \\
(\% R H)\end{array}$ & $\begin{array}{l}\text { Response/ } \\
\text { recovery time } \\
\text { (s) }\end{array}$ & $\begin{array}{l}\text { Fabrication } \\
\text { methods }\end{array}$ & $\begin{array}{l}\Delta R / R_{0}(\%) \\
/(\% R H)\end{array}$ & Ref. \\
\hline$R G O / P U$ & $10-70$ & $3.5 / 7$ & $\begin{array}{l}\text { Thermal annealing } \\
\text { of GO }\end{array}$ & $4.7 / 38$ & 1 \\
\hline Graphene/polypyrrole & $12-90$ & $15 / 20$ & $\begin{array}{l}\text { Chemical oxidative } \\
\text { polymerization }\end{array}$ & $159 / 52$ & 2 \\
\hline RGO/PDDA & $11-97$ & $108 / 94$ & $\begin{array}{l}\text { Layer-by-layer } \\
\text { self-assembly }\end{array}$ & $25 / 75$ & 3 \\
\hline CNT/PI & $20-90$ & $5 / \sim 600$ & $\begin{array}{l}\text { In situ } \\
\text { polymerization }\end{array}$ & $6.7 / 70$ & 4 \\
\hline PANI & $11-95$ & $760 / 170$ & $\begin{array}{l}\text { Pre-stretching } \\
\& \text { self-assembly }\end{array}$ & - & 5 \\
\hline$W S_{2}$ & $20-90$ & $5 / 6$ & $\begin{array}{l}\text { Tungsten } \\
\text { sulfurization }\end{array}$ & $21000 / 45$ & 6 \\
\hline $\mathrm{MoS}_{2}$ & $0-35$ & $10 / 60$ & CVD & $40 / 10$ & 7 \\
\hline $\mathrm{LiCl} / \mathrm{TiO}_{2}$ & $11-95$ & $3 / 7$ & Electrospun & - & 8 \\
\hline GO & $8-95$ & $3 / 7.7$ & Chemically derived & $5307 / 95$ & This work \\
\hline
\end{tabular}

In this table, PU, PDDA, CNT, PI and PANI are the abbreviations of polyurethane, poly(diallylimethyammonium chloride), carbon nanotube, polyimide and polyaniline, respectively. 
Table S2. Detection ranges of the humidity sensor at different temperatures.

\begin{tabular}{|l|l|}
\hline Temperature $\left({ }^{\circ} \mathrm{C}\right)$ & Detection range $(\% \mathrm{RH})$ \\
\hline $\mathbf{2 6}$ & $8-95$ \\
\hline $\mathbf{4 9}$ & $8-95$ \\
\hline $\mathbf{7 3}$ & $21-95$ \\
\hline $\mathbf{1 0 5}$ & $35-95$ \\
\hline
\end{tabular}




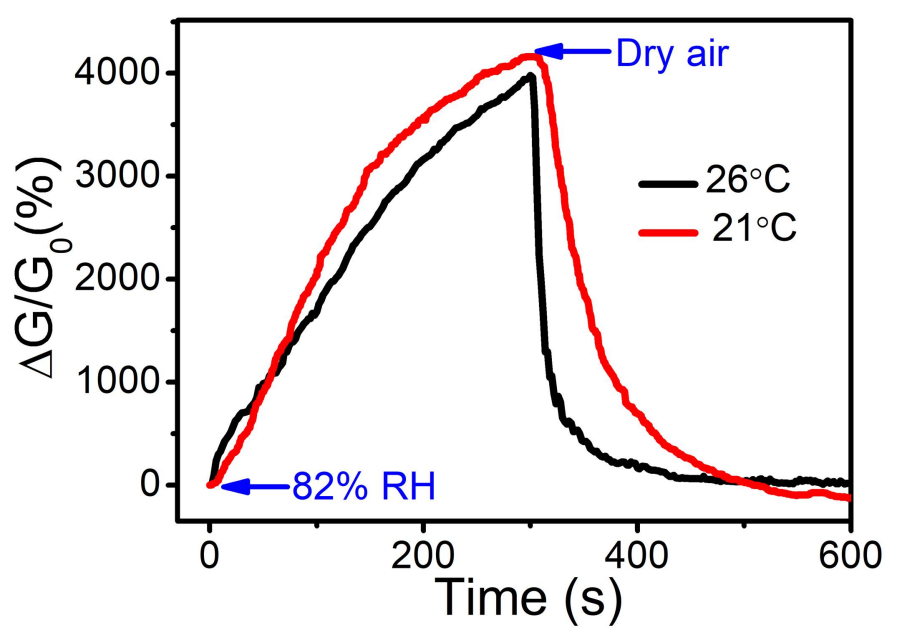

Figure S8. Comparison in the dynamic responses of the humidity sensor to $82 \% \mathrm{RH}$ at 21 and $26^{\circ} \mathrm{C}$. 

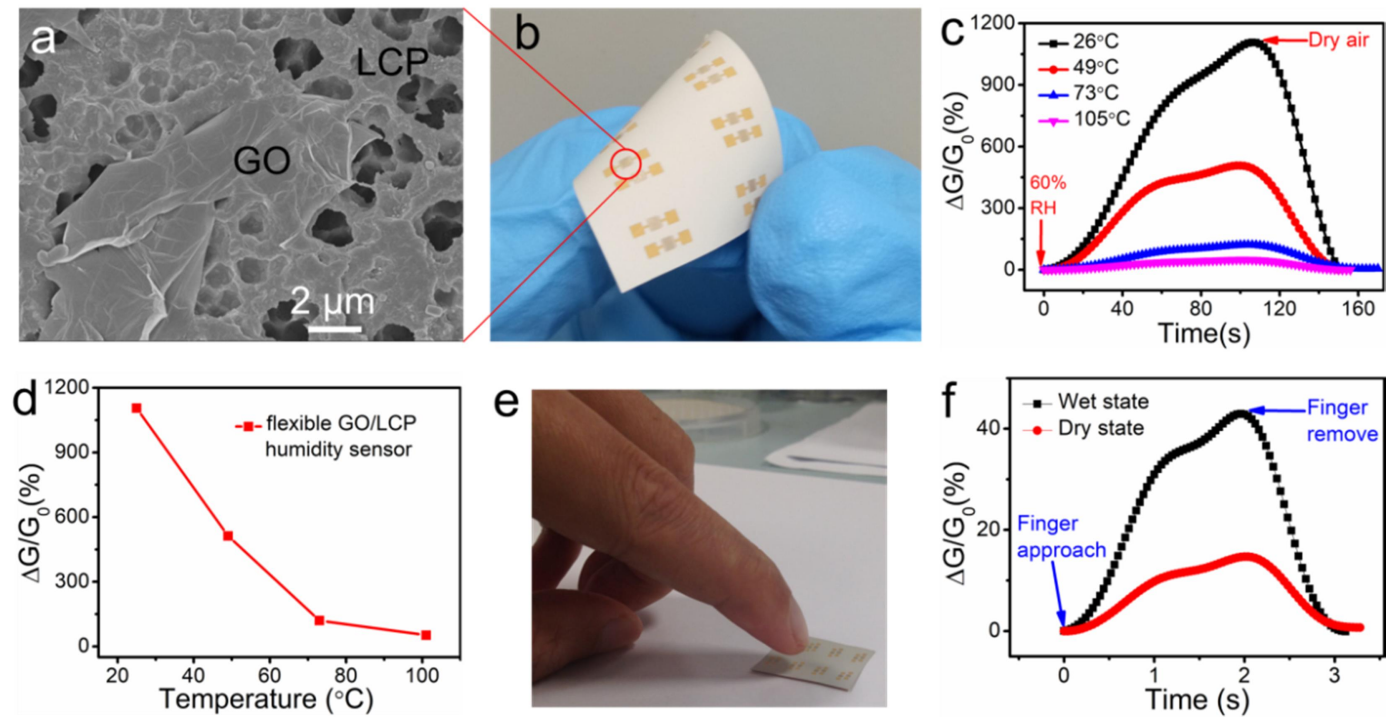

Figure S9. a) SEM image of 2D GO sheets deposited on a porous LCP substrate. b)

Photograph of the flexible GO-based humidity sensor fabricated on the LCP substrate.

c) Dynamic responses of the GO/LCP humidity sensor to $60 \% \mathrm{RH}$ at different temperatures. d) Response of the flexible sensor to $60 \%$ RH versus temperature. e) Photograph showing the approach of a fingertip to the GO/LCP humidity sensor. f) Dynamic responses of the GO/LCP humidity sensor to the approach of a fingertip at wet and dry states, respectively. 


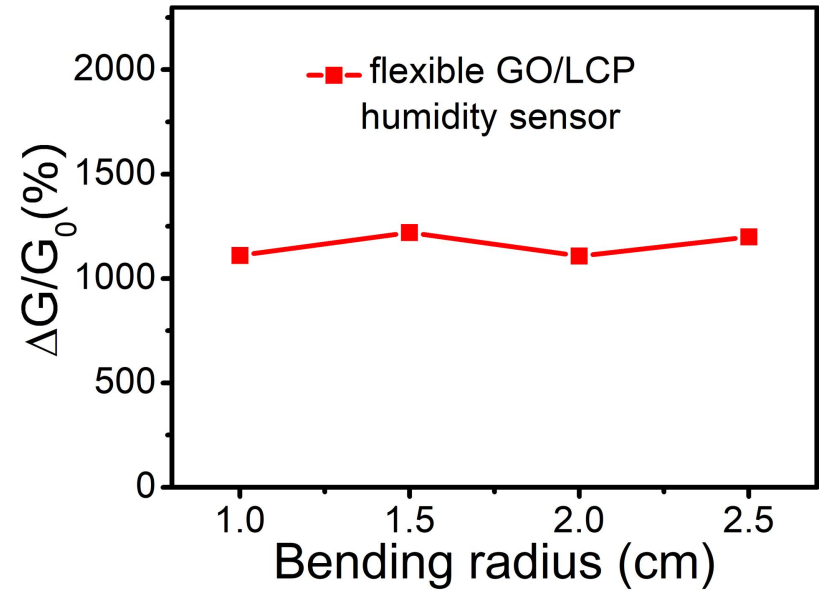

Figure S10. Plot of the response of the flexible GO/LCP humidity sensor to $60 \% \mathrm{RH}$ versus the bending radius. 


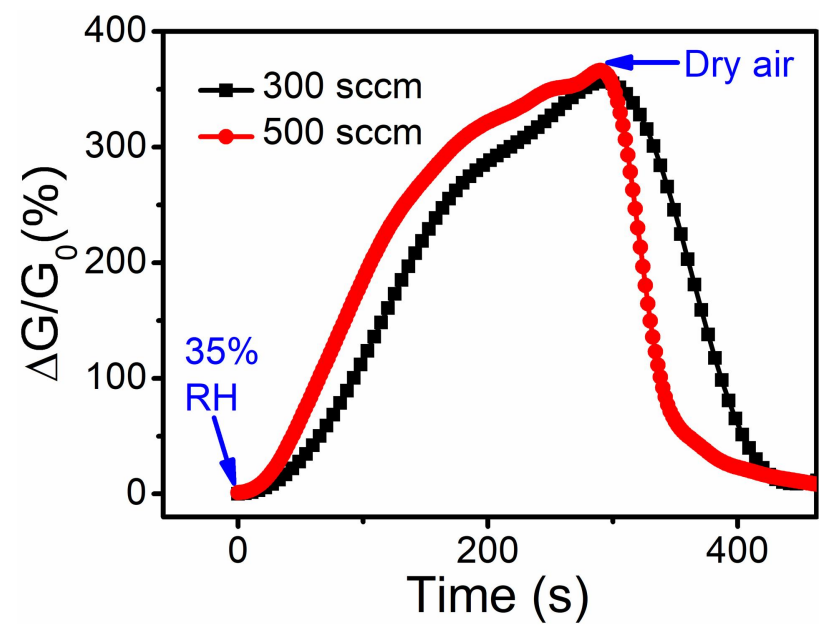

Figure S11. Comparison in the dynamic responses of the humidity sensor to $35 \% \mathrm{RH}$ under the flow rates of 300 and $500 \mathrm{sccm}$, respectively. 


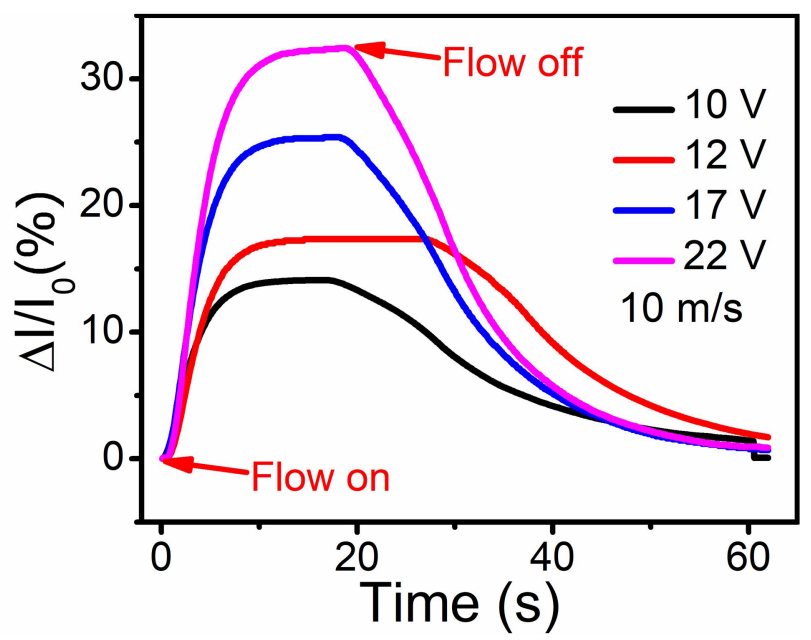

Figure S12. Overlapping dynamic response curves of the flow sensor to $10 \mathrm{~m} / \mathrm{s}$ at different voltages. 


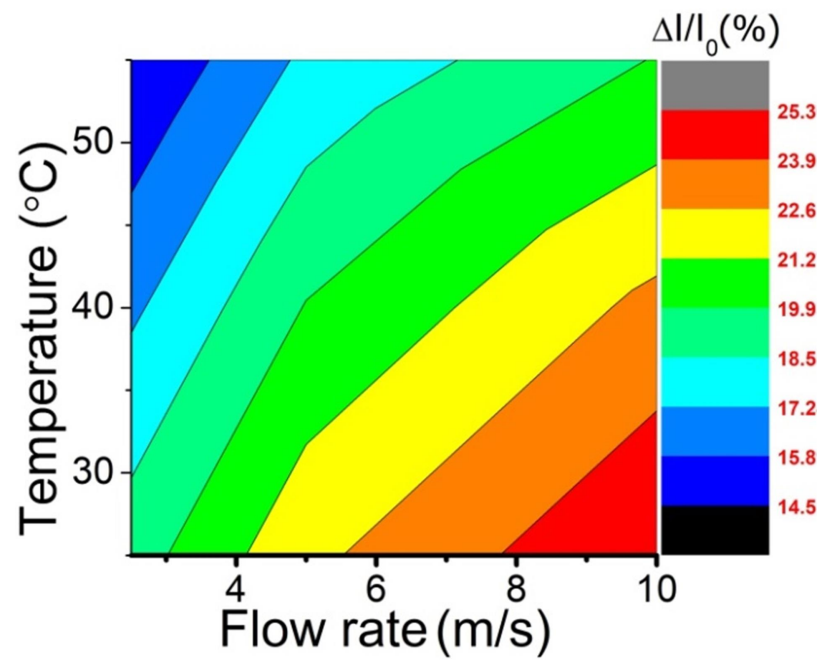

Figure S13. Responses of the flow sensor under different flow rates and temperatures. 


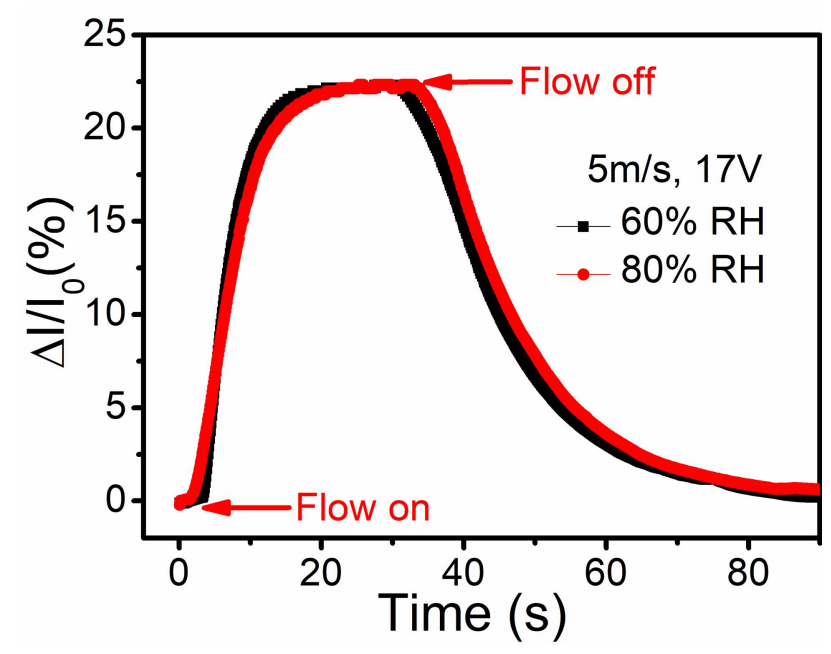

Figure S14. Dynamic responses of the flow sensors to $5 \mathrm{~m} / \mathrm{s}$ flow at different humidity when the voltage of $17 \mathrm{~V}$ was applied on the microheater. 


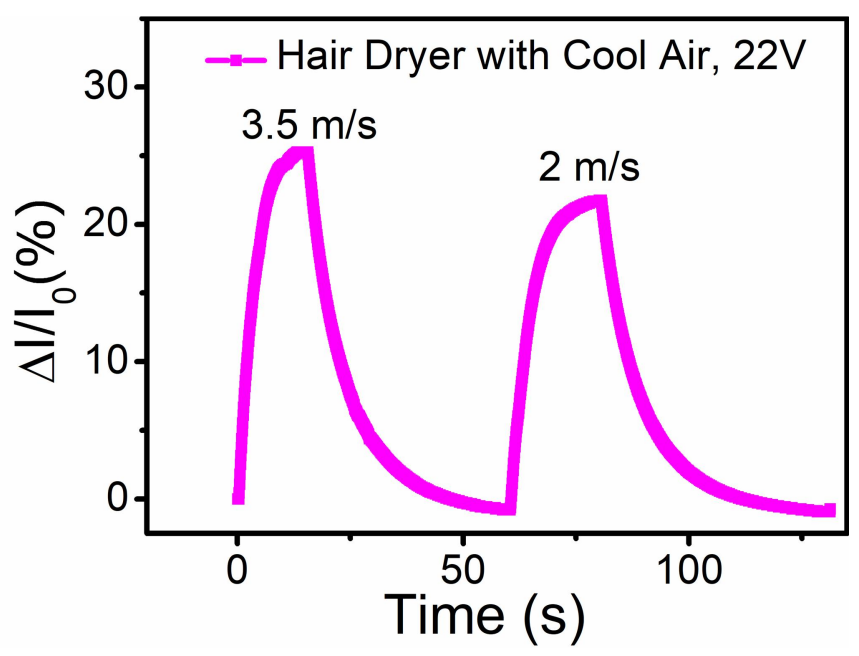

Figure S15. Dynamic response of the flow sensor to the blow from the hair dryer with the flow rates of 3.5 and $2 \mathrm{~m} / \mathrm{s}$. The response to $3.5 \mathrm{~m} / \mathrm{s}$ wind was larger than that to 2 $\mathrm{m} / \mathrm{s}$, indicating the ability to distinguish different wind speed. 

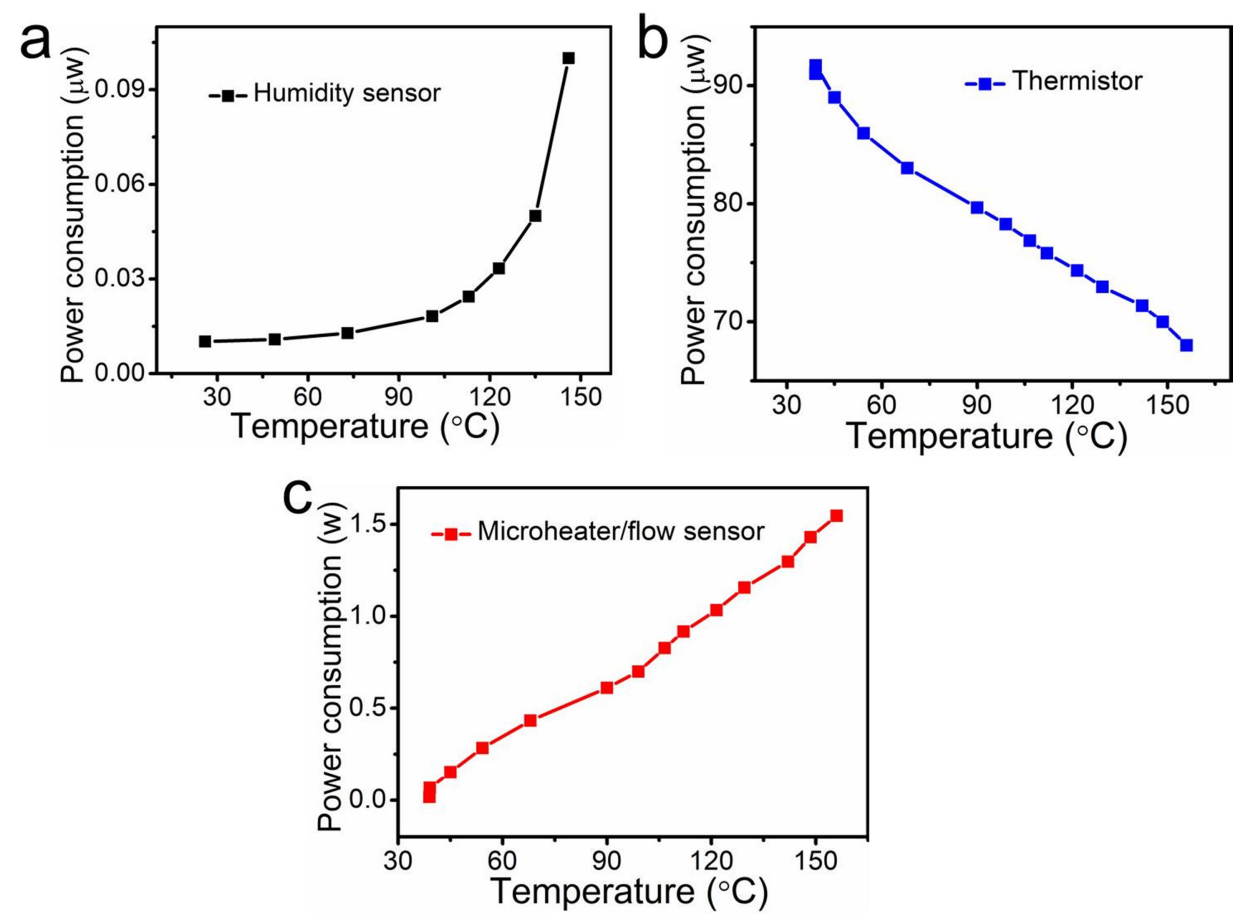

Figure S16. Power consumptions of the humidity sensor (a), temperature sensor (b), and microheater/flow sensor (c) at different substrate temperatures. 

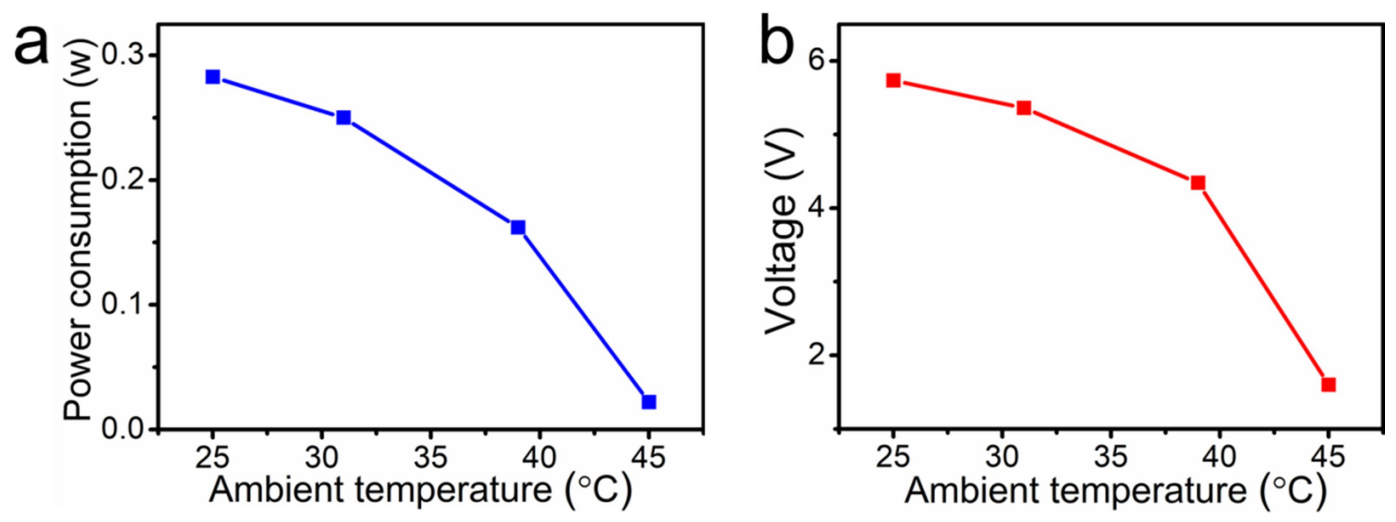

Figure S17. The power consumption (a) and voltage (b) on the microheater required to maintain the chip temperature at $54.2{ }^{\circ} \mathrm{C}$ under different ambient temperatures. 


\section{REFERENCES}

(1) Trung, T. Q.; Duy, L. T.; Ramasundaram, S.; Lee, N.-E. Transparent, Stretchable, and Rapid-Response Humidity Sensor for Body-Attachable Wearable Electronics. Nano Res. 2017, 10, 2021-2033.

(2) Lin, W.-D.; Chang, H.-M.; Wu, R.-J. Applied Novel Sensing Material Graphene/Polypyrrole for Humidity Sensor. Sens. Actuators, B 2013, 181, 326-331.

(3) Zhang, D.; Tong, J.; Xia, B. Humidity-Sensing Properties of Chemically Reduced Graphene Oxide/Polymer Nanocomposite Film Sensor Based on Layer-by-Layer Nano Self-Assembly. Sens. Actuators, B 2014, 197, 66-72.

(4) Tang, Q.-Y.; Chan, Y. C.; Zhang, K. Fast Response Resistive Humidity Sensitivity of Polyimide/Multiwall Carbon Nanotube Composite Films. Sens. Actuators, B 2011, 152, 99-106.

(5) Ryu, H.; Cho, S. J.; Kim, B.; Lim, G. A Stretchable Humidity Sensor Based on a Wrinkled Polyaniline Nanostructure. RSC Adv. 2014, 4, 39767-39770.

(6) Guo, H.; Lan, C.; Zhou, Z.; Sun, P.; Wei, D.; Li, C. Transparent, Flexible, and Stretchable $\mathrm{WS}_{2}$ Based Humidity Sensors for Electronic Skin. Nanoscale 2017, 9, 6246-6253.

(7) Zhao, J.; Li, N.; Yu, H.; Wei, Z.; Liao, M.; Chen, P.; Wang, S.; Shi, D.; Sun, Q.; Zhang, G. Highly Sensitive $\mathrm{MoS}_{2}$ Humidity Sensors Array for Noncontact Sensation. Adv. Mater. 2017, 29, 1606151.

(8) Li, Z. Y.; Zhang, H. N.; Zheng, W.; Wang, W.; Huang, H. M.; Wang, C.; MacDiarmid, A. G.; Wei, Y. Highly Sensitive and Stable Humidity Nanosensors 
Based on LiCl Doped $\mathrm{TiO}_{2}$ Electrospun Nanofibers. J. Am. Chem. Soc. 2008, 130, 5036-5037. 